\title{
Arctic thermokarst lakes and the carbon cycle
}

\author{
Mary Edwards' ${ }^{1}$, K. Walter ${ }^{2}$, G. Grosse ${ }^{3}$, L. Plug ${ }^{4}$, L. Slater ${ }^{5}$ and P. Valdes ${ }^{6}$
}

'School of Geography, University of Southampton, UK; M.E.Edwards@soton.ac.uk

${ }^{2}$ Water and Environmental Research Center, University of Alaska, Fairbanks, USA; ${ }^{3}$ Geophysical Institute, University of Alaska, Fairbanks, USA; ${ }^{4}$ Department of Earth Sciences, Dalhousie University, Halifax, Canada; ${ }^{5}$ Department of Earth and Environmental Science, Rutgers University, Newark, USA; ${ }^{6}$ School of Geographical Sciences, University of Bristol, UK.

Arctic thermokarst lakes may be a significant carbon source during interglacial periods. A new IPY study will better quantify their current dynamics and model their past and future contributions to the carbon budget.

\section{Methane emission from thermokarst lakes}

Methane, a major greenhouse gas (GHG), is produced in the anerobic bottoms of wetlands and lakes through microbial decomposition of organic matter. Methane escapes to the atmosphere via plants, molecular diffusion, and ebullition (bubbling). Recent observations have shown that certain Arctic thermokast lakes (TKL) have particularly high rates of methane emission (Zimov et al., 1997; Walter et al., 2006; 2007a). TKL form in Arctic regions where ice-bearing permafrost warms and thaws due to a local change in ground conditions and/or regional climate change. This can trigger melting of ground ice, surface collapse and the development of lakes in the resulting basins. TKL deepen and expand due to thermal and mechanical erosion of shore banks. Such lakes have formed intermittently across Arctic landscapes throughout the last $14 \mathrm{kyr}$ since deglaciation (Romanovskii et al., 2000; Walter et al., 2007b).

Today, TKL tend to be relatively small but numerous, and lakes may cover 20$40 \%$ of the land surface in some regions, notably the unglaciated terrain of northeast Siberia and Alaska (Fig. 1). TKL often undergo a dynamic cycle of formation and drainage. Once formed, they expand with continued thawing of surrounding soils. Eventually, expansion leads to catastrophic drainage into streams, other lakes or the sea, as a result of tapping, gully erosion along melting ice wedges, or erosion after overflow during snowmelt. Lake drainage results in suberial basins that support terrestrial or wetland vegetation types. Over time, new permafrost aggrades in the drained basins, which can support the formation of new lakes in these basins. The presence in some areas of large, deep lakes dating to the early Holocene and extensive lake basins suggest that thaw-lake initiation earlier in the Holocene resulted in much larger lakes than those that exist today. It is possible that climate warming will lead to increased lake development and thus to increased methane emissions, adding to the greenhouse effect and generating a positive feedback on climate warming. It is therefore important to learn

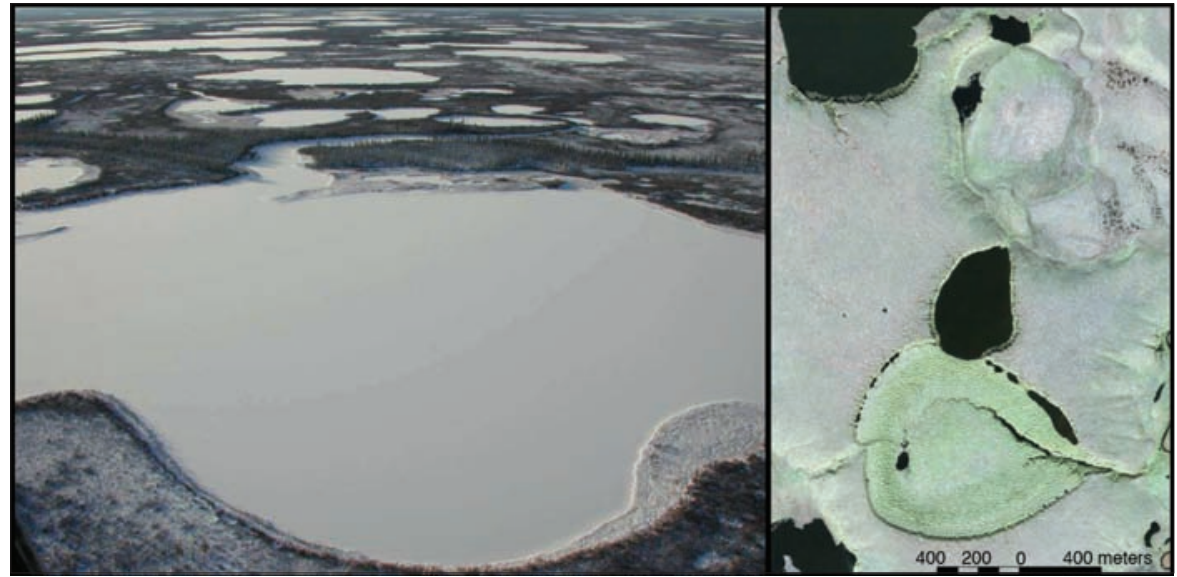

Figure 1: Left, oblique aerial view of TKL in NE Siberia (photo K.M. Walter). The lake is ca. 300 m across; Right, high-resolution IKONOS image of TKL and drained basins on the Seward Peninsula, Alaska. as much as possible about this methaneproducing system.

\section{Temporal development of thermokarst lakes}

TKL are predominantly interglacial phenomena. Although thaw-lake deposits are reported from glacial-age sediments, most radiocarbon dates associated with thaw-lake sediments are of late-glacial or
Holocene age. Several thaw-lake deposits are also described from the last interglaciation (Edwards and McDowell, 1991; Andreev et al., 2004; Ilyashuk et al., 2006). The dating record suggests that lake formation was particularly dynamic during the early Holocene. If the considerable flux of methane observed from these lakes today is typical, TKL may have been a globally important source of atmospheric meth-

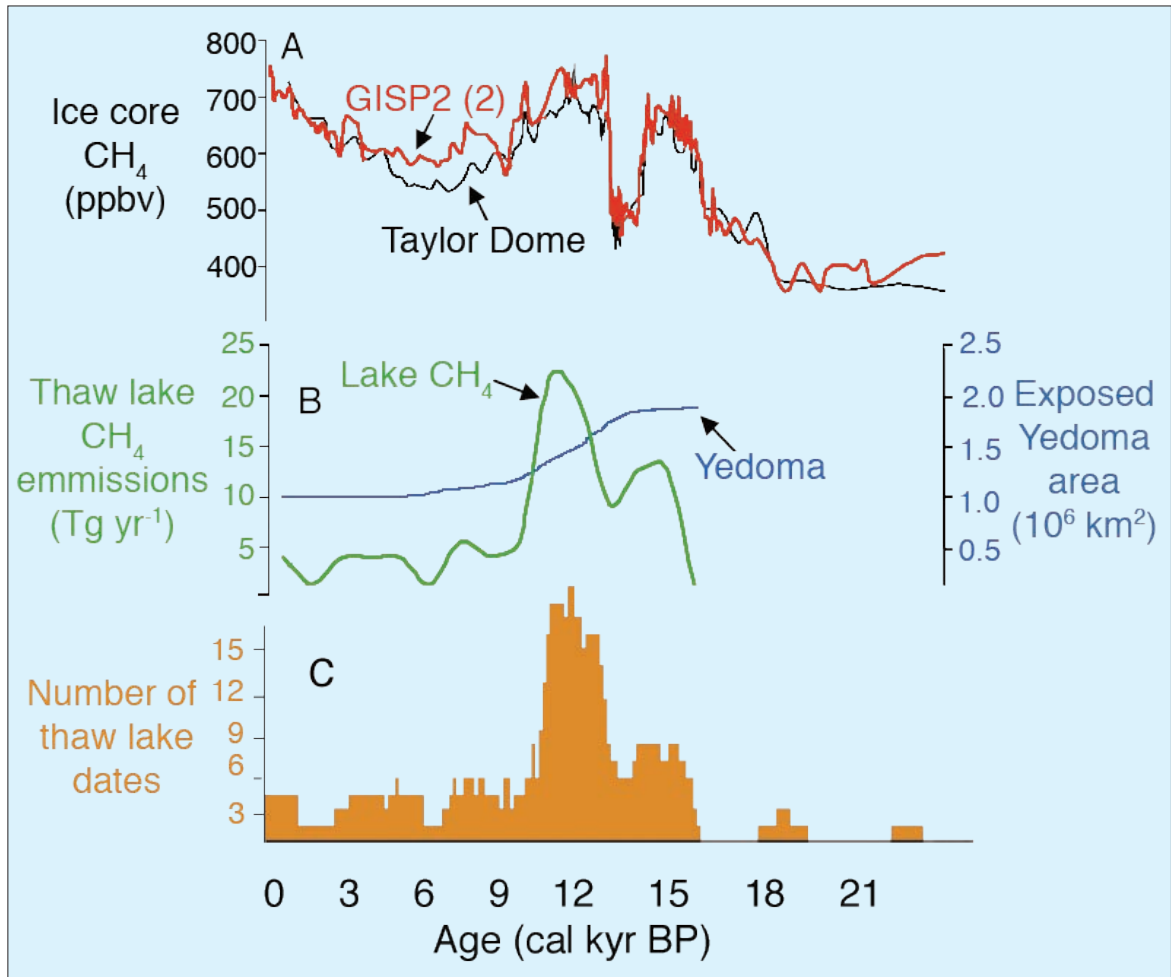

Figure 2: $\boldsymbol{A})$ Holocene atmospheric methane levels from ice-core data. B) Estimated emissions from TKL related to number of incipient lakes and the area of N. Siberian shelf inundated during the early Holocene marine highstand. "Yedoma" refers to ice-rich deposits that occupy large areas of N. Siberia, including the shelf regions covered by a marine transgression during deglaciation. C) Radiocarbon-dated thaw-lake deposits; Figure after Walter et al. 20076 . 


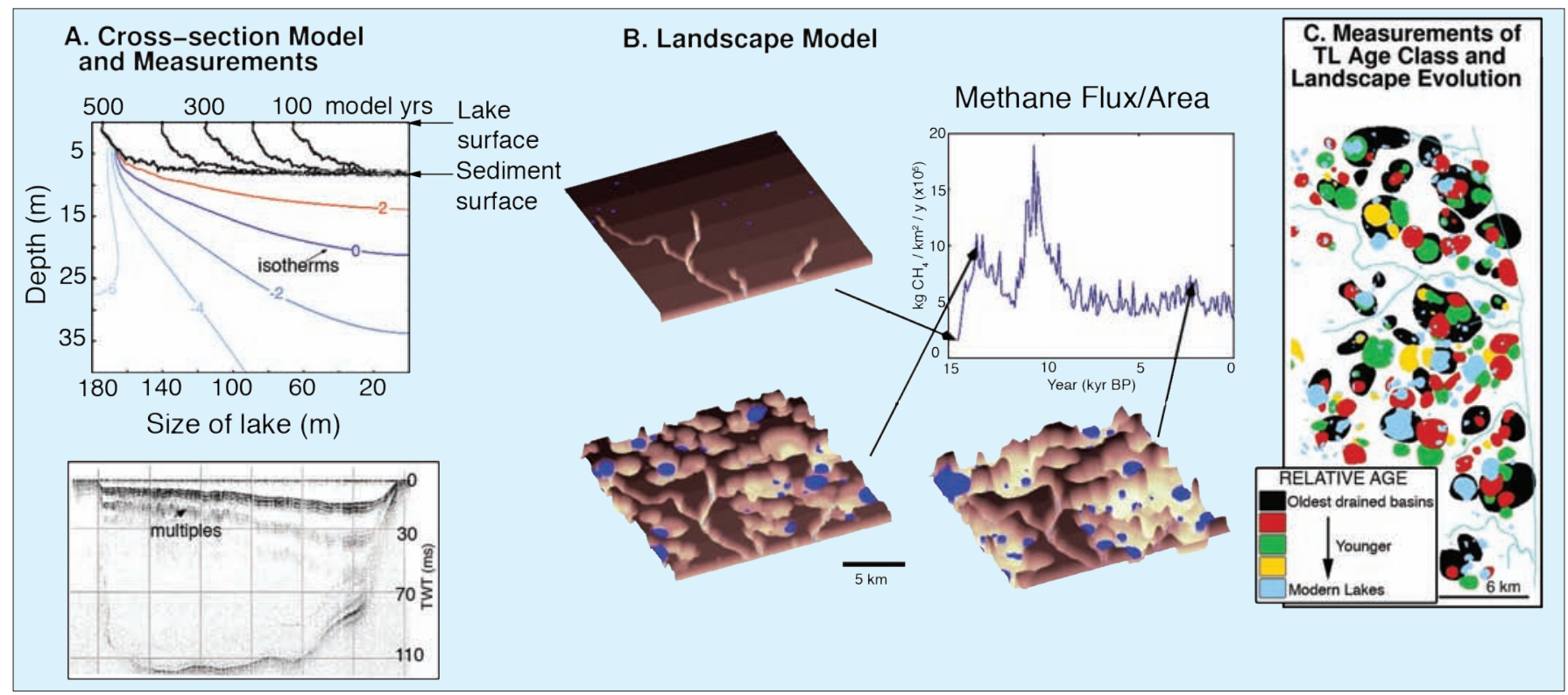

Figure 3: Components of the thaw-lake process model. A) Upper panel shows a model of the thermal and geomorphic evolution of a single Thermokarst Lake (TKL) in cross-section. Black lines represent lake-margin position of a right-to-left expanding lake at 100-yr-intervals, blue/red lines indicate ground temperature contours after 500 yr (isotherms), Lower panel is a shallow seismic/GPR imaging of talik and lake sediment (image shows lake and talik of Lake Nikolai, from Schwamborn et al., 2000). TWT: Two-Way-Time. B) The 3D Landscape Model: conceptual illustrations of the landscape at different times in a simulation, and a plot of a hypothetical methane flux for the Holocene. C) Elements of a TKL landscape classified into age classes, constrained by ${ }^{14} \mathrm{C}$ dates and paleo-studies. This will be used to test the 3D model using spatial statistics (example shown is from the Northern Seward Peninsula study area).

ane during deglaciation and throughout the Holocene (Walter et al., 2007b; Fig. 2).

Although TKL have been studied for decades, until recently most interest had been in the processes shaping their formation rather than their role in biogeochemical cycles and the climate system (but see work by Billings and Petersen, 1980, and Hinkel et al., 2003 on the role of drained lake basins as carbon sinks). Our study is focused on the relationship between permafrost degradation, thaw-lake development and the carbon cycle. In particular, we aim to resolve the magnitude of methane release from lakes to the atmosphere during the late Quaternary, and in the future as climate continues to warm.

\section{New research}

Two projects, funded by NSF IPY (PI: Walter) and NASA Carbon Cycle Sciences (PI: Grosse), respectively, began during the summer of 2008. They involve three interlinked goals. The first component is a modern process study involving (i) Mapping and classification of contemporary TKL and the landscapes in which they are found, (ii) Identification of pathways of carbon release and storage, and (iii) Development of process models of thawlake formation, development and carbon cycling. In this way we will improve upon the first-approximation estimates of Walter et al. (2006) as to the current contribution of TKL to the global atmospheric methane budget. Quantification of gas fluxes will be integrated with the activities of Flagship Observatories in the Arctic Observing Network (AON) in Alaska, Russia, and Sweden (Arctic Ob- serving Network; http://aon.iab.uaf.edu/ index.html). We are establishing a new Pan-Arctic Lake-Ice Methane Monitoring Network (PALIMMN) collaboratively with ongoing Arctic projects and through outreach and education (Student-PALIMMN) (www.alaska.edu/uaf/cem/ine/walter/ ongoing_projects.xml). These will be related to data compiled from a range of remote sensing analyses to develop maps and a classification of themokarst and TKL for regions of Alaska and Siberia (Grosse et al., 2006). Remote sensing tools will be used to quantify the trajectory of spatial thaw lake dynamics during the last 55 years and to monitor methane emissions from TKL using a variety of radar sensors (Walter et al., 2008).

The second component involves assembling paleoenvironmental data to test our argument that thaw-lake formation in Siberia and Alaska can explain a significant proportion of northern hemisphere methane emissions during the Holocene deglaciation. Field studies of lake development through time, based on dated sediment profiles of current and paleo-lake basins, will be central to the paleoenvironmental component of the study. These will be complemented by high-resolution measurements of electrical resistivity/induced polarization and ground-penetrating radar (GPR), and seismic observations of thawed sediments underlying lake beds ("talik"). Furthermore, assays of carbon content and methane production potential of a range of lacustrine and terrestrial sediments observed in thaw-lake basins will allow better quantification of these lakes as both sources and sinks of carbon through time. These data are critical to the development of numerical process models (see below), which will simulate thaw-lake dynamics under a range of environmental conditions.

The final part of the project involves projecting the dynamics and related GHG emissions of thaw-lake cycling into the future as permafrost warms and thaws under global warming. This requires modeling, for which two process models are being developed: (i) A single-lake model, which simulates the dynamics of a lake basin (West and Plug, 2008; Plug and West, in press), and (ii) A landscape model, which includes hill-slope processes, surface water movement, and landscape-scale permafrost dynamics.

The models will first be validated by comparison with observed modern landscapes. Subsequently, simulations of late-Quaternary lake development will be evaluated against the observed temporal patterns available from stratigraphic and paleoenvironmental records. We have the possibility to use both transient climate simulations from the fast Earth-System model FAMOUS (Jones et al., 2005) for 21-0 kyr BP and Holocene time-slices from regional paleoclimate model simulations for Beringia (Edwards et al., 2006). We can then assess the effectiveness of these modeling hierarchies at simulating past conditions. The final step in modeling will be the coupling of the thaw-lake process models with the higher resolution HADCM3 (Johns et al., 2003) for simulations of the period 2000-2200 AD. 


\section{References}

Grosse, G., Schirrmeister, L. and Malthus, T.J. 2006: Application of Landsat-7 satellite data and a DEM for the quantification of thermokarst-affected terrain types in the periglacial Lena-Anabar coastal lowland, Polar Research, 25: 51-67.

Plug, L.J. and West, J.J., in press: Thaw lake expansion in a twodimensional coupled model of heat transfer, thaw subsidence and mass movement, Journal of Geophysical Research, doi:10.1029/2006JF000740
Romanovskii, N.N., Hubberten, H.-W., Gavrilov, A.V., Tumskoy, V.E., Tipenko, G.S., Grigoriev, M.N. and Siegert, C., 2000: Thermokarst and Land-Ocean Interactions, Laptev Sea Region, Russia, Permafrost and Periglacial Processes, 11: 137-152.

Walter, K.M. Zimov, S.A., Chanton, J.P. Verbyla, D. and Chapin F.S., 2006 Methane bubbling from Siberian thaw lakes as a positive feedback to climate warming, Nature, $443 ;$ : 71-75.
Walter, K.M., Edwards, M.E., Grosse, G., Zimov, S.A. and Chapin F.S.III., 2007b: Thermokarst lakes as a source of atmospheric $\mathrm{CH}_{4}$ during the last deglaciation, Science, 318: 633-636.

For full references please consult:

www.pages-igbp.org/products/newsletters/ref2009_1.htm

\title{
Initial results of HOTRAX address a wide range of Arctic paleoclimate issues
}

\author{
Dennis A. Darby ${ }^{1}$, L. Polyak ${ }^{2}$ and M. Jakobsson ${ }^{3}$
}

'Deptartment of Ocean, Earth and Atmospheric Sciences, Old Dominion University, Norfolk, USA; ddarby@odu.edu

2Byrd Polar Research Center, Ohio State University, Columbus, USA; 'BDeptartment of Geology and Geochemistry, Stockholm University, Sweden

\section{The Healy-Oden Trans-Arctic Expedition (HOTRAX'05) obtained an exceptional collection of sediment cores from across the Arctic Ocean to address the key unresolved issues of Arctic paleoceanography.}

The HOTRAX expedition retrieved 21 jumbo piston cores averaging $\sim 12 \mathrm{~m}$ in length from a complete transect across the Arctic Ocean, in combination with multibeam bathymetric surveys and chirp-sonar subbottom profiling, and 8 cores of up to $16 \mathrm{~m}$ in length from the continental margin off Alaska (Fig. 1). These Alaskan margin cores have extremely high sedimentation rates $(1.5 \mathrm{~m} / \mathrm{kyr})$ that provide unprecedented Holocene paleoceanographic records, while the central Arctic cores provide records that permit comparisons between earlier warm intervals and those of the Holocene. Together with previously collected core material, we are now better able to grasp the complex array of sediment archives in the Arctic Ocean and to address the important issues of past climate change.

The paleoclimate record in the Arctic has been sorely lacking compared to the rest of the World Ocean because of the difficulties in obtaining quality Arctic records. Even with the greatly improved technology, which includes better icebreakers, coring equipment, improved multibeam and chirp profilers critical for locating potential core sites, and, yes, even with the warming climate providing record low ice extent in the last two years, challenges exist that are unique to the Arctic. HOTRAX made significant strides in providing quality records but more will be required in order to overcome the obstacles to a comprehensive Arctic paleoclimate history.

Climate change in the Arctic commands the close attention of the scientific community as average temperatures in the Arctic over the past 30 years have increased at almost twice the rate of the planet as a whole and sea ice is disappearing at alarming rates. Climate models based on these observations suggest that the Arctic is rapidly moving toward a new, low-ice or even seasonally ice-free state that has not been witnessed in human history. In fact, data from long drill cores recovered by the Arctic Coring Expedition (ACEX; Fig. 1) from the Lomonosov Ridge suggest that the Arctic perennial ice cover may have been around for at least $14 \mathrm{Myr}$ (Darby, 2008). Its disappearance would be a truly monumental change, going far beyond human history.

Of course, the core recovery and resolution of sampling in the ACEX drill cores, upon which this is based, are not sufficient to confirm that there were no ice-free periods over this long time interval. Evidence of past reduced ice cover has been documented from coastal Arctic records from the Miocene (Williams et al., 2008), at least part of the Pliocene, and some of the Quaternary Interglacials (e.g., BrighamGrette and Carter, 1992; CAPE members, 2006) and the early Holocene (England et al, in press; Funder and Kjaer, 2007). This highlights the need for higher resolution records in the Arctic Ocean covering as much of the Cenozoic as possible. To understand the range of variability for future Arctic climates, we need to explore paleoclimate archives with a special focus on

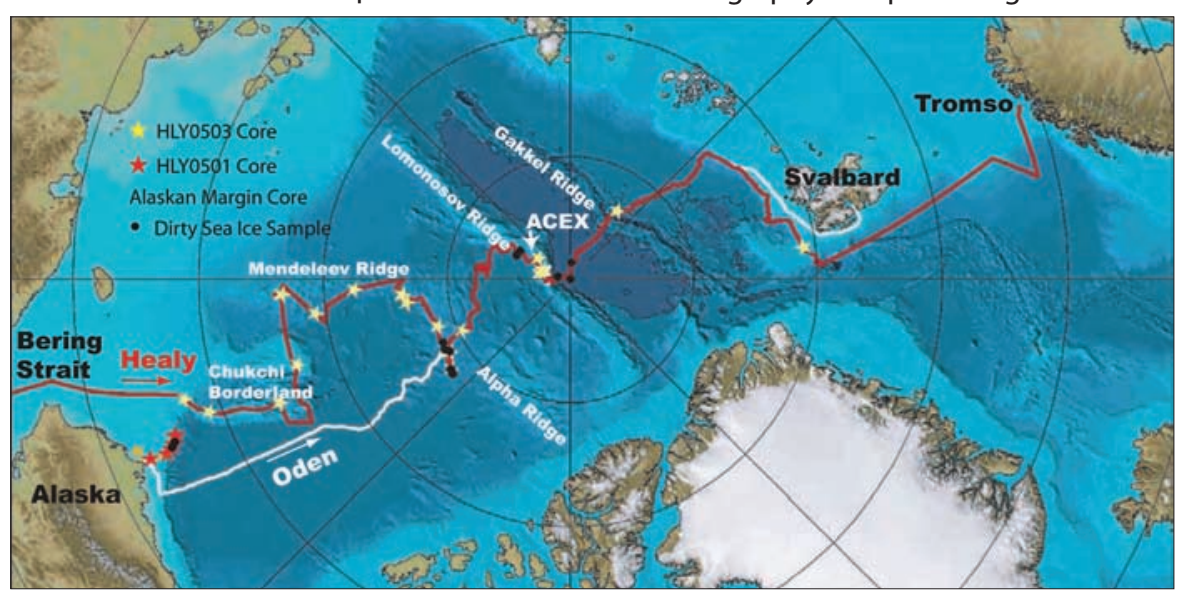

Figure 1: International Bathymetric Chart of the Arctic Ocean (Jakobsson et al., 2008) showing core locations from the Healy-Oden Trans-Arctic Expedition (HOTRAX) in 2005. At each core site, in addition to the 10-cm-diameter piston core and gravity trigger core (2-3 $m$ in length), there is a multicore consisting of 7-8 half-m-long tubes containing the sediment water interface. Black circles indicate the location of several dirty sea-ice samples collected during HOTRAX (used to provide insights on sea ice drift). low-ice periods of the recent geological past. Great strides have been made with the Greenland ice core records (Bond et al., 1993; Calder et al., 2008) but for all the advances they have brought, the Arctic Ocean record of change is still critical because the Greenland records appear to be more closely linked to the North Atlantic than the Arctic, and it is this single ocean that serves as the primary heat sink for the northern hemisphere.

The initial results of work on the HOTRAX cores and other Arctic archives are being prepared for publication in a special issue of Global and Planetary Change (GPC). In another special issue celebrating IPY slated for publication later this year in the Canadian Journal of Earth Science, there are three papers based on HOTRAX cores. Because stratigraphy and age control are the foundation of any paleoclimate history, these special issues have several HOTRAX papers focusing on this topic. A variety of tools are used to determine the age models for these sediment records including AMS radiocarbon dating, ${ }^{210} \mathrm{~Pb},{ }^{10} \mathrm{Be}$, amino-acid racemization rates, luminescence, biostratigraphy and paleomagnetic inten- 